Mangiaracina, R., Perego, A., Perotti, S., Tumino, A. (2016), "Assessing the environmental impact of logistics in online and offline B2c purchasing processes in the apparel industry", International Journal of Logistics Systems and Management, Vol. 23, No. 1, pp. 98-124.

DOI: 10.1504/IJLSM.2016.073300

\title{
Assessing the environmental impact of logistics in online and offline B2c purchasing
}

\section{processes in the apparel industry}

Riccardo Mangiaracina, Alessandro Perego, Sara Perotti* and Angela Tumino

Politecnico di Milano, Department of Management, Economics and Industrial Engineering

Via Lambruschini 4/B

20156 Milano, Italy

* Corresponding author (email: sara.perotti@polimi.it; tel: +39 022399 6876)

\begin{abstract}
This paper presents an Activity-Based model for the assessment of the environmental impact of the purchasing process in the apparel industry, comparing traditional in-store and B2c e-commerce channels with a focus on logistics activities. Interviews with company managers and secondary sources were used to develop and validate the model. A base case was selected and applied, and a sensitivity analysis was carried out. Based on the model results, the base case online purchasing process was found to be to be more sustainable than the offline one, due to the lower environmental impact of the Pre-sale and sale and the Delivery phases. The impact of logistics is generally very high in both the online and offline purchasing processes (i.e. $99 \%$ and $62 \%$ of total $\mathrm{CO}_{2 \mathrm{e}}$ emissions respectively). In the online case, the location of the consumer house (i.e. inside or outside the city centre) is the parameter with the greatest environmental impact, whereas in the offline case the distance between the consumer house and the store was identified as the most significant factor. The paper addresses an identified need to quantify the environmental effects of the offline versus online purchasing channels, and logistics activities in particular. From a managerial viewpoint, the model can help practitioners understand the environmental consequences of their business and can support internal monitoring procedures.
\end{abstract}

Keywords: B2c e-commerce; logistics; environmental sustainability; quantitative model. 
Despite the bursting of the Dotcom bubble in 2000, over the last ten years B2c e-commerce has grown in all of the main western markets. The most important factors in this success include the wide range of products (Park et al., 2012), very competitive prices (Bruce and Daly, 2010), the design of a high quality customer experience (Brugnoli et al., 2009), the choice of the best logistics strategy (Ghezzi et al., 2012), and the premium service level (primarily in the management of returns) offered by online retailers (Wei and Zhou, 2011). In addition to these elements, which are mainly related to the retailer strategy, there are various systemic factors that are usually considered to drive the diffusion of e-commerce (Mangiaracina et al., 2012). Examples of these include broadband availability, the definition of a legal framework for consumer protection, the design of a “secure" value proposition (Rodiguez-Ardura et al., 2008), trust in online systems (Mouratidis and Cofta, 2010), and the adoption of different payment systems (Mangiaracina and Perego, 2009).

Among the various sectors that produced interesting results, the apparel industry certainly demonstrated the most growth over the last 5 years, and in many countries it was the industry with the largest online-sales value in 2013 (eMarketer, 2013; Evans, 2010; Mulpuru, 2013). This sector is traditionally affected by a significant level of complexity, largely related to factors such as uncertain product demand, i.e. in terms of variability and volatility of customer orders (e.g. Qudrat-Ullah, H., 2013) and the 'seasonal' model (autumnwinter; spring-summer) that fashion companies usually adopt in their business concept (García-Arca and PradoPrado, 2010). This complexity has also implications in terms of logistics operations (e.g. management of stock levels given uncertainty and variability in volume, mix and delivery; risk of obsolescence, with products to be sold off, or sold in promotions), the effects of which are reflected throughout the entire supply chain and affect its organisational structure.

In recent years, a debate has begun in the literature on the role of the sustainability of online shopping compared to conventional shopping (i.e. in physical stores) in boosting the spread of e-commerce. Overall, sustainability is considered to be a key factor that can help firms to improve operations and strategic growth while at the same time gaining a Sustained Competitive Advantage (SCA) (Hart and Milstein, 2003; Porter and Kramer, 2006; Samarrokhi et al., 2014). According to the Triple Bottom Line (TBL) approach, sustainability must take into account three components: natural environment, society, and economic performance. Considering people and the planet in addition to profit leads to a more sustainable outcome (Colicchia et al., 2013; Elkington, 1994; Perotti et al., 2012), and company performance can be improved by balancing profits with social and environmental goals (Hart and Milstein, 2003; Porter and Kramer, 2006; Shao and Liu 2012). However, a number of barriers have been identified that may hamper company adoption of green practices. As an example, 
lack of commitment from top management, lack of market demand, lack of preparedness on the part of suppliers, inadequate strategic planning, or lack of appropriate environmental performance metrics have been found by Mudgal et al. (2010) to be among the main hurdles.

With specific reference to e-commerce, several interesting themes have been debated in the literature. Specifically, the environmental implications of e-commerce (e.g. in terms of distribution network design, transport planning and management, warehousing), metrics and tools for measuring the environmental impact of e-commerce, and differences between online and conventional shopping from a 'green' perspective have been discussed in depth. Still, much remains to be done in this respect. First, the literature refers primarily to industries such as books and grocery, whereas sectors such as apparel (e.g. Zeng and Xu, 2010) and consumer electronics have either been only partially considered to-date or have not been examined at all. Secondly, although some previous contributions have presented comparisons between e-commerce and conventional shopping, only a few have addressed the topic of environmental sustainability, and only a minority have included the logistics perspective.

Consistently with the above premises, the purpose of this paper is to develop a quantitative model for assessing the environmental impacts (i.e. measured as $\mathrm{kg} \mathrm{CO}_{2 \mathrm{e}}$ ) of the purchasing process (i.e. from the pre-sale to the post-sale activity) in the apparel industry, comparing offline and online channels. The approach taken focuses specifically on logistics activities (i.e. transport and warehousing), as these activities are recognised as being crucial to the environmental sustainability of the entire purchasing process (Hjort et al., 2013). This paper addresses an identified need to provide quantitative evidence of the environmental implications of the logistics activities that underlie both offline and online purchasing channels.

The remainder of the paper is organised as follows. Section 2 presents the literature review, while objectives, research questions and the methodology used in this study are described in Section 3. Section 4 provides a description of the processes examined. Sections 5 and 6, respectively, present the description of the model and its application. Finally, conclusions are presented and potential directions for future research in this field are discussed.

\section{Literature review}

\subsection{The environmental impact of online and offline B2c purchasing}

The literature offers an abundance of contributions in the arena of sustainability and Green Supply Chain Management (GSCM) and Practices (GSCP), with different research methods being used. For example, Smith (2012) examines two medium-to-large Ohio-based manufacturing companies by adopting case study- 
perspective. The paper illustrates how these companies are working to apply best business practices towards sustainability via incremental greener and leaner approaches. With a different purpose and methodology, Mangla et al. (2014) use a multi objective decision-making tool based on interpretative structural modelling to examine how a number of variables (such as supplier and stakeholder commitment, cost benefits, regulations and standards, organisation-specific barriers, market share, etc.) impact on the effective implementation of green practices in supply chains.

However, within this broad context, the environmental effects of e-commerce processes and logisticsrelated activities have seldom been investigated. Overall, the literature does not offer a general consensus on the environmental impact of the online and offline channels, and their related activities. As highlighted by McKinnon et al. (2012), the outcomes are highly dependent on the specific context (i.e. particular circumstances and situations). In general, both pros and cons can be identified for B2c e-commerce compared to the offline channel. On the one hand, there appears to be a widely held opinion among consumers that online purchases and home delivery are good for the environment as they reduce personal travel demand. Moreover, offline purchasing has to account for the issue of unsold items, which can generate significant extra flows between stores and warehouses, with consequent additional transport (Matthews et al., 2001). To strengthen this perception, some online retailers have been actively publicising the environmental benefits of online shopping (Smithers, 2007).

On the other hand, B2c e-commerce has sometimes been called to account for its related environmental consequences. In fact, online retailing can have wide-ranging environmental effects due to a number of factors such as an increase Information Technology (IT) usage, the redesign or use of additional packaging (Williams and Tagami, 2003), and the physical distribution of items. Among these factors, logistics activities such as transport and warehousing represent a key component of the environmental sustainability of the entire supply chain (McKinnon, 2012). For example, focusing on transport-related impacts, the increasing growth of online purchasing and home delivery has contributed to recent growth in van traffic (Commission for Integrated Transport, 2010), vehicles that consume more fuel and release more emissions per tonne moved than larger vehicles. Second, unattended (i.e. failed) deliveries (McLeod et al., 2006) and handling of consumer returns (e.g. Park and Regan, 2004) involve further travel, additional warehousing operations, and related greenhouse gas (GHG) emissions, the significance of which may vary depending on the industry sector. For example, according to Ghezzi et al. (2012), return rates can be up to 30 per cent of total online sales, and apparel has one of the highest rates of returns. Third, consumers usually tend to purchase separate items from different web-based companies, each requiring independent deliveries (unlike the offline channel, where goods are bought on a single 
trip to the stores). The same occurs when purchasing multiple items (from one retailer) that are stored at different warehouses, thus involving separate deliveries. Finally, there are other critical environmental aspects associated with online purchasing, such as: minimal travel savings by shopping online when goods would have been bought as part of a multi-activity trip if purchased via the offline channel (Primerano et al., 2008); in warehouses, the need for additional sorting to combine multiple consumer orders prior to delivery (de Koster, 2002).

Due to both its specific warehousing and handling needs, as well as the high incidence of returns and unsold items in stores, apparel is an industry that has some of the most demanding and challenging logistics requirements (Ghezzi et al. 2012), which could have a significant impact on the sustainability of the purchasing process. All of these factors make conducting a comparison between the online and the offline channels in the apparel industry very interesting.

\subsection{Modelling the impact of online versus offline purchasing: a 'green' perspective}

Several contributions in the literature have highlighted the need to measure the environmental impact of e-commerce processes, thus comparing them with the conventional channel (e.g. Edwards et al., 2010). Quantitative models were found on the assessment of the environmental implications of e-commerce beginning in 2001 (e.g. Matthews et al., 2001; Taniguchi and Kakimoto, 2003). As an example, Taniguchi and Kakimoto (2003) proposed a model of vehicle routing and scheduling to evaluate the effects of e-commerce on both urban freight transport and the environment (i.e. measured in terms of NOx emissions), highlighting the advantages of pick-up points compared to direct deliveries. More recently, Sivaraman et al. (2007) provided a comparative lifecycle assessment (LCA) of two competing digital video disc (DVD) rental networks, i.e. the e-commerce option, where the customer orders the movies online, and the traditional business option, where the customer goes to the rental store to rent a movie. A comparison is performed in terms of their environmental and economic benefits and costs. Results show that the e-commerce alternative consumed $33 \%$ less energy and emitted $40 \%$ less $\mathrm{CO}_{2}$ than the traditional option.

However, these models have some limitations that should be addressed. Most of them are incomplete, as they tend to focus on specific phases of the purchasing process, i.e. chiefly on transport (e.g. last mile delivery), instead of taking into account the process as a whole and its related environmental impact. In some cases, activities are not adequately modelled in detail, thus affecting the overall accuracy of the model. Finally, to the best of the authors' knowledge, no studies have been undertaken to measure the environmental impact of online and offline B2c purchasing processes in the apparel industry. This represents a significant gap since, according to several sources, fashion represents up to $25 \%$ in the B2c e-commerce arena, and a thorough 
examination from this perspective is recommended. Although a number of studies have been found on environmental sustainability in the fashion supply chain (e.g. Caniato et al., 2012), these studies had a different purpose and they neither focused on e-commerce, nor provided quantitative data based on process modelling.

\section{$3 \quad$ Objectives and methodology}

The research presented in this paper is a part of a broader study on environmental sustainability in the B2c e-commerce channel. The proposed model aims to overcome some of the gaps and limitations identified in the literature review by assessing the environmental impact of both online and offline purchasing processes in the apparel sector, with a particular focus on logistics activities. A comparison between the two channels is made in order to understand whether and when the online purchasing process is more environmentally sustainable than the offline one.

To reach the aforementioned objective, the following research questions were identified:

RQ1. How can the online and the offline purchasing processes be modelled in the apparel industry?

RQ2. How can the environmental impact of both the online and offline purchasing processes be modelled and assessed?

RQ3. What is the role of logistics activities in determining the environmental impact of the online and offline purchasing processes?

RQ4. What are the main parameters affecting the impact of logistics activities? How does the environmental impact change by varying these parameters?

In order to develop a model that is generally valid, an analytical approach was chosen, due to its flexibility (i.e. changes and modifications can be applied to each single modelled activity with limited effort) and transparency (i.e. hypotheses are clear and evident from the equations).

The model was developed and applied using a three-phase methodology. The first phase involved the description of the purchasing process for both the online and offline scenarios, with a specific focus on the downstream supply chain (i.e. from the retailer warehouse to the final consumer) (Brugnoli et al., 2009). The online and offline processes were examined in detail in order to identify the main phases involved. Two main sources were used: a literature review on the structure of the purchasing process and interviews with supply chain managers at 10 large retailers in the apparel industry that have both physical stores and a B2c e-commerce website. The outcome of this first phase was the identification of four main macro-activities for each channel: Pre-sale and sale, Order picking and assembly, Delivery, Post-sale for the online purchasing process and Store 
replenishment, Pre-sale and Sale, Delivery, Post-Sale for the offline purchasing process. The processes are presented in detail in section 4 .

The second phase consisted of modelling the environmental impact - measured in terms of $\mathrm{CO}_{2}$ equivalent $\left(\mathrm{kgCO}_{2} \mathrm{e}\right)$ emissions -ascribed to the purchasing processes identified in phase 1. Three main sources were used:(i) a literature review on the assessment of $\mathrm{CO}_{2 \mathrm{e}}$ emissions; (ii)interviews conducted with both the aforementioned 10 large retailers in the apparel industry and 3 express couriers, in order to collect detailed information on the activities that contribute to the overall environmental impact of the process; (iii) analysis of secondary sources, such as studies that report the environmental impacts of electric energy consumption and of fundamental activities such as transportation, warehousing, and handling (e.g. Defra, 2012). The outcome of this phase was: (i) the modelling of the environmental impact of all of the basic activities involved in both the online and the offline purchasing processes, according to an Activity-Based approach as suggested in the literature (e.g. McKinnon et al., 2012); (ii) the determination of the inputs and the contextual data required to run the model. A detailed description of the model is presented in section 5 .

In the third phase, the model was applied to a base case, based on average data obtained from the interviews. Different scenarios were identified based on both the type of consumer and retailer, and on the distance between the consumer house and the retailer store. A sensitivity analysis was then performed to assess variations in some of the key parameters, namely: the distance between the consumer house and the store, the location of the consumer house, and the number of items ordered. The detailed application of the model is presented in section 6 .

\section{The purchasing processes}

Based on both the results of the literature review and the interviews with the 10 retailers, the purchasing process has been broken down into its main component parts for both the online and the offline scenarios, thus resolvingRQ1.

For the online purchasing process, the following four main phases were identified:

- Pre-sale and Sale. This phase includes all of the activities carried out during the garment selection process and involves both the retailer and the consumer. It begins when the consumer accesses the Internet and ends with the payment, including the search for an item using search-engines, browsing on the retailer website, item selection, the main actions conducted when the item is in the cart (e.g. filling out a form with personal data, choosing a delivery method, payment), and the possible interactions between the retailer and the consumer via email and/or phone. Some of these activities may be carried out only once or multiple times, 
according to the purchasing behaviour of the consumer. The order is assumed to consist of only one folded (and not hung) item. In order to maintain consistency when assessing the environmental impacts, an item is considered to have been folded in both the online and offline channels. As it was assumed that the process starts with the consumer intent to purchase, communication activities undertaken by the retailer during the pre-sale phase were not included in this study, in either the online or the offline case.

- $\quad$ Order picking and assembly. This phase begins upon receipt of the order at the retailer warehouse and ends with cartons ready to be picked up by the courier in the shipping area. It includes activities such as picking and packing of the item. According to the main findings from the interviews, the following assumptions have been made in modelling the picking activity:(i) the storage area (where the garments are stored in baskets) is shared with the offline channel; (ii) picker-to-part, low-level systems, are used where pickers travel along the aisles and pick single items using a man-on-board truck;(iii) a batch picking policy is used, followed by manual sorting. The packing activity is assumed to be conducted manually in a dedicated area, with the support of a simple handling system consisting of conveyors. The cartons that are ready to be picked up by the express courier are then placed in the shipping area.

- Delivery. This phase begins when the cartons are picked up by couriers at the retailer warehouse and ends with delivery at the consumer house. It includes all of the main activities performed by the courier (i.e. transport from the retailer warehouse to the courier receiving hub and handling at the hub, transport to the shipping hub and handling at the hub) and the possible interactions between the courier and the consumer to provide/acquire information about the order tracking. According to the main findings of the interviews, it was assumed that: (i) cartons are picked up at the retailer warehouse using trucks;(ii) handling at the two hubs is fully automated, with conveyors feeding the sorters; (iii) the transport from the receiving hub to the distribution hub is full truck load (using 28t semi-trailers); (iv) the delivery is carried out using vans.

- Post-Sale. This phase is made up of activities that may or may not take place, according to the specific case and, moreover, depending on the consumer behaviour. The trigger for post-sales activities is the consumer intention to return the item and it is assumed that the objective is the replacement of the purchased item. Given this premise, this phase starts out with a request for a return and ends with the delivery of the new item to the consumer house. It includes all of the activities undertaken by the consumer in order to prepare the return (i.e. packaging and labelling), those carried out by the retailer to store the returned item (i.e. item receiving and reconditioning, storing) and to fulfil the new order (i.e. additional order picking and packing activity), as well as the new delivery carried out by the express courier.

Similarly to the online process, the offline purchasing process was organised into four main phases: 
- Store replenishment. This phase includes all of the activities required to replenish a store. It begins with the replenishment order made by the store manager and ends with the replenishment of the shelves in the store. It also includes release of the picking list, and picking, packing and shipping of the goods. It is assumed that the retailer has a single warehouse that serves both the online and offline channels. The assumptions related to picking activities are similar to those made for the retailer warehouse in the online purchasing process, the exception being that sorting is performed using an automatic sorter. The orders are subsequently packed at the end of the sorter chutes and moved to the shipping area where they are loaded onto a 3,5t truck that, depending on the order size and consequent saturation, can serve one or more stores with a multi-drop policy. As soon as the truck arrives at the store, items are offloaded, and put either in the backroom or straight onto the shelves.

- $\quad$ Pre-sale and Sale. This phase begins when the consumer leaves their home to go to the store by car and ends with the payment for the item. It includes the consumer search for the item, interactions between the consumer and the salesperson, and trying on the item in the fitting room. These activities may take place only once or several times, depending on the purchasing behaviour of the consumer. In the offline case, the order is also assumed to consist of only one folded (and not hung) item.

- Delivery. The delivery phase consists of the consumer trip back home by car from the store.

- Post-sale. Similarly to what happens in the online process, this phase consists of activities that are not mandatory and are influenced by different factors (i.e. consumer behaviour, whether the garment meets consumer expectations, quality of the items, etc.). The main assumption that is made is that the action required is always the replacement of the item purchased. According to this premise, the Post-sale phase begins with the consumer coming back to the store to return the item and replace it. It includes the trip to the store and the return trip home, new interactions with the salesperson, and it could also involve an additional visit to the fitting room.

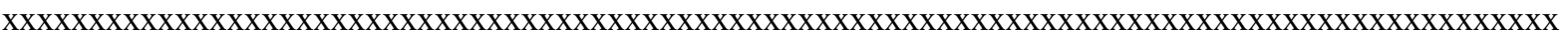
Take in Figure 1

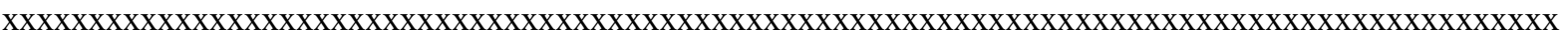

\section{$5 \quad$ Proposed model}

Figure 2 shows the architecture of the model, which is organised into four main sections: inputs, i.e. where the user fills in the data required to run the model; contextual data, i.e. where all of the data referring to the external 
context have been collected and categorised; model algorithms, i.e. where the mathematical formulas are applied to assess the environmental impact related to each individual activity in the process; outputs, i.e. where the results are displayed in tables and on graphs. Each of these sections is presented and discussed in the subsequent paragraphs, thereby answering RQ2.

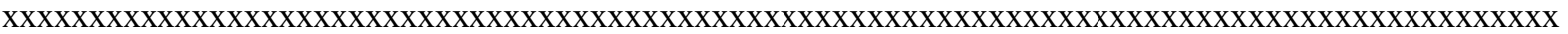
Take in Figure 2

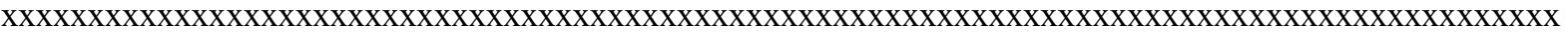

\subsection{Model Inputs}

The input section consists of four main categories of data:

- features of the retailer warehouse, i.e. size of the warehouse $\left[\mathrm{m}^{2}\right]$, number of orders fulfilled per day, building energy rating;

- features of the retailer store, i.e. size of the store $\left[\mathrm{m}^{2}\right]$, daily consumer flow, incidence of unsold items [\%], incidence of returns [\%], building energy rating;

- consumer features, i.e. data related to the consumer profile (e.g. number of both websites and stores visited before purchasing, number of items tried on before making a selection, number of interactions with the online retailer via email, number of interactions with the salesperson in the store) and the location of the consumer house (i.e. urban or extra-urban area);

- $\quad$ average distance between the consumer house and the retailer store.

\subsection{Contextual data}

Contextual data were grouped into four categories:

- Energy consumption [kWh], i.e. conversion factors related to both machinery and buildings;

- $\mathrm{CO}_{2 e}$ emissions $[\mathrm{kgCO}$ e], i.e. activity-based conversion factors (e.g. Defra, 2011) related to machinery (e.g. material handling equipment in the warehouse), means of transport and buildings (i.e. retailer warehouses and points of sale, and consumer house) considered in the model;

- $\quad$ Times $[s]$, i.e. the elementary times required to conduct each activity(e.g. the time required in the warehouse to fulfil an order);

- Logistics and transport features, i.e. data related to the volumes handled and the distances travelled by the logistics service providers/express couriers. Please note that this type of information has been included 
among the contextual data since the model assumes the retailer perspective. As such, the selection of a logistics services provider is seen as an exogenous factor that normally cannot be modified in the short term by the retailer.

\subsection{Assessment of the environmental impact}

The environmental impact was modelled for each individual activity that takes place in both the online and the offline processes. As an example, Table 1presents the main equations used to assess the environmental impact of the delivery phase in the online purchasing process. Five pieces of information are used to characterise each activity:

- activity description, which provides a brief summary of the specific activity;

- $\quad$ activity type, which identifies the macro-area in which the activity belongs (i.e. purchasing, communication, management, transportation, picking, packaging, warehousing);

- channel, through which the activity is conducted (i.e. online or offline);

- $\quad$ player, that carries out the activity (i.e. consumer, retailer, express courier);

- equations/mathematical formulas, which describe how $\mathrm{CO}_{2 \mathrm{e}}$ emissions were computed for each activity.

Although the equations are composed of two terms, i.e. the driver that generates the environmental impact and the related $\mathrm{CO}_{2 \mathrm{e}}$ emissions, their complexity can vary significantly depending on the algorithm required to model the driver.

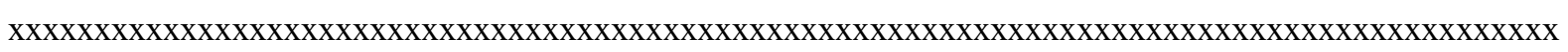

Take in Table 1

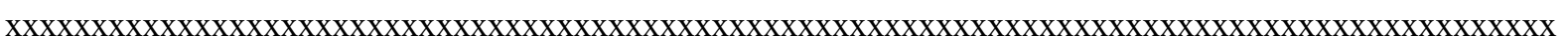

\subsection{Model Outputs}

As an output, the model produces a spread sheet that contains links to tables and graphs displaying the results. Graphs and tables can be selected according to different views and aggregation levels. First of all, the output spread sheet shows the environmental impact of the purchasing process in both the online and offline scenarios. This overall result can then be broken down into its individual component parts:

- Macro-activity, to understand the role of each macro-activity in generating $\mathrm{CO}_{2 \mathrm{e}}$ emissions and to compare the results of the online and offline cases; 
- Activity type, to identify the contribution of each activity type to the $\mathrm{CO}_{2 \mathrm{e}}$ emissions;

- Player, to assess and compare the impact of each individual player on the environmental impact of the entire purchasing process;

- Channel, to identify the contribution to the environmental impact of the channel used to support each individual activity.

\section{Application of the model}

\subsection{Structure of the analysis}

The model was applied to a base case, in which the contextual data were selected to represent typical online and offline purchasing processes involving a consumer and a retailer in the apparel sector.

The contextual data related to express couriers and the times required for different activities were parameterised using the following procedure. Preliminary data were first collected through face-to-face interviews with the express couriers and retailers involved in the research project. Then, the base case was validated with industry experts. In terms of the contextual data related to energy consumption and $\mathrm{CO}_{2}$ emissions, the parameterisation was based on a review of reports and secondary sources (e.g. Defra, 2013; ENEA, 2010). A selection of the main contextual data is presented in Table 2.

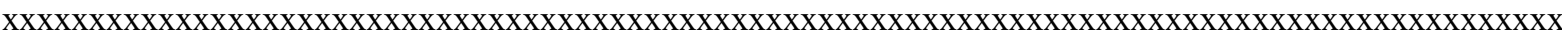

Take in Table 2

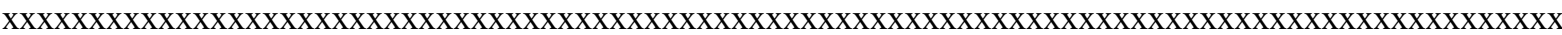

Different scenarios were taken into account as shown by the model inputs. First, since the model involves both the consumer and the retailer (i.e. main players in the purchasing process), it is important to understand how the environmental impact changes by varying their features. In order to accomplish this task, different consumer and retailer profiles were considered. With regard to the consumer, 3 different attitudes were identified based on the literature review (Cardoso et al, 2010) and these are reported in Table 3:

- "fashion addicted" consumer, i.e. a consumer who compares a large number of purchasing alternatives, visiting different e-commerce websites/stores, trying on many garments with a significant number of interactions with sales clerks before making a decision, easily returning (in the online purchasing process) the product if it does not fulfil his/her needs/desires; 
- "moderate" consumer, i.e. a consumer who displays standard purchasing behaviour, visiting a limited number of websites/stores (i.e. those he/she is familiar with), trying on only those garments that he/she is really interested in, asking questions only when it is really needed, and returning the product (in the online case) when the size is not correct or the colour is not consistent with that shown on the e-commerce website;

- "apathetic" consumer, i.e. a consumer with no specific needs aside from minimising the time involved in the decision process. This consumer returns the product (in the online case) only if there are major problems (e.g. defective product) or when the size is completely inappropriate.

Second, the input data related to the retailer were obtained through the interviews with top management at the 10 retailers mentioned in Section 3. Three different alternatives - i.e. high, medium, low - representing an upper bound, an average case, and a lower bound, respectively, were established for each of the following parameters: size (measured by the warehouse area, and the number of orders fulfilled per day both online and offline), unsold rate at the store, and store size (measured by the store area and the flow of people) as shown in Table 3 . The energy rating for both the warehouse and the store has been set to "E", since this is the most common case. The scenarios identified are pre-set and are intended to be representative cases to be assessed using the model. However, the values for each input parameter can be entered individually, providing a tool that is tailored to meet the specific needs of the user.

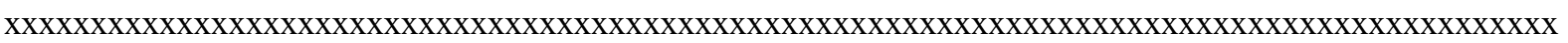
Take in Table 3

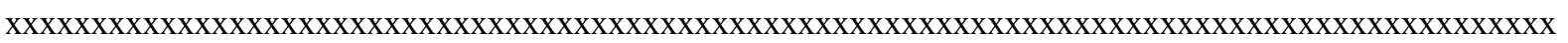

\subsection{Application of the model to the base case}

The model has been applied to a base case, in which:

- the input data related to the retailer were all set to medium values;

- those of the consumer represent the "moderate" scenario;

- the consumer house is located in the city centre;

- the average distance between the consumer house and the store is set to $7 \mathrm{~km}$, obtained as the average distance among those found in the literature (e.g. Edwards et al., 2010; Kim et al., 2008; Scott Matthews et al., 2001; Scott Matthews et al., 2002; Sivaraman et al., 2007; Weber et al., 2010; Wiese et al., 2012).

In this scenario, the environmental impact of the online purchasing process is significantly lower than the impact of the offline case - 2,95 $\mathrm{kgCO}_{2 \mathrm{e}} \mathrm{vs} .6,62 \mathrm{~kg} \mathrm{CO}_{2 \mathrm{e}}$ - as shown in Figure 3. 
To better clarify the main reasons for this substantial difference, each individual activity needs to be examined, beginning with those that are involved in both processes:

- $\quad$ Pre-sale and sale. In the offline process, this phase produces $3.89 \mathrm{kgCO}_{2 \mathrm{e}}$, or almost $60 \%$ of the overall environmental impact of the entire offline purchasing process. This is due to both the high impact of transport from the consumer house to the store $-1.49 \mathrm{kgCO}_{2 \mathrm{e}}$ related to emissions from the car - and the sales process in the store $-3.4 \mathrm{kgCO}_{2 \mathrm{e}}$ mainly related to the building energy consumption (both heating and cooling). The Pre-sale and sale phase in the online purchasing process produces only $0.03 \mathrm{kgCO}_{2 \mathrm{e}}$, since the activities conducted by the consumer are mainly computer-based and therefore have a negligible environmental impact.

- Delivery. The environmental impact related to this activity in the online purchasing process $\left(0.99 \mathrm{kgCO}_{2 \mathrm{e}}\right.$, of $33 \%$ of the overall impact of the process) is lower than the impact of the same activity in the offline case $\left(1.49 \mathrm{kgCO}_{2 \mathrm{e}}\right.$, or $22 \%$ of the overall impact of the process). This is due to the greater efficiency of last mile delivery (online case) when the consumer is in the city centre (high delivery density in a urban area, with more than 40 drops by the courier along a delivery route).

- Post-sale. The environmental impact of this activity in the online process $(0.71 \mathrm{kgCO} 2 \mathrm{e}$, or $24 \%$ of the overall impact of the process $)$ is higher than in the offline case $\left(0.11 \mathrm{~kg} \mathrm{CO}_{2 \mathrm{e}}\right.$, or $2 \%$ of the overall impact of the process) due to the relevance of the online return rate, which is significant in the apparel industry and generates additional activities (pick up of the returned product, picking, packing and delivery of the new one). The post-sale activity in the offline process is negligible, due to the very low rate of returns at stores. With regard to the activities that are specific to each of the two processes (i.e. order picking and assembly for the online process and the store replenishment for the offline one) the following results were obtained:

- $\quad$ Order picking and assembly (online purchasing process). This activity contributes the most to generating $\mathrm{CO}_{2 \mathrm{e}}$ emissions in the online process with $1.22 \mathrm{kgCO}_{2}$, i.e. $42 \%$ of the overall impact. The order picking and assembly activity has a significant impact because the features of the online order entail the handling and packing of individual pieces. 
- Store replenishment (offline purchasing process). This activity generates $1.12 \mathrm{kgCO}_{2 \mathrm{e}}$, i.e. $17 \%$ of the overall environmental impact of the offline purchasing process. It includes the picking of products in the warehouse, transport to the store and replenishment of the shelves.

Looking at the results from a different perspective, the environmental impact of the online and offline processes may be divided into non-logistics and logistics activities (i.e. transport, handling, packing and warehousing), thus answering RQ3 and RQ4. The results show that the impact of logistics is extremely high in the online purchasing process (i.e. $99 \%$ of total $\mathrm{CO}_{2 \mathrm{e}}$ emissions are attributed to logistics activities) and high for the offline process (62\%).

A comparison of the online and the offline cases produced three main results. First, transport activities have a greater impact in the offline case $\left(3.13 \mathrm{kgCO}_{2 \mathrm{e}}\right.$, i.e. $47 \%$ of total emissions for the entire process) than in the online case $\left(0.98 \mathrm{kgCO}_{2 \text { e }}\right.$, i.e. $33 \%$ of total emissions $)$, mainly due to inefficiencies related to transport to and from the store compared to home delivery by express couriers in the online case. Second, handling activities have a greater impact in the online case $\left(1.13 \mathrm{kgCO}_{2}\right.$, i.e. $38 \%$ of total emissions $)$ than in the offline case $(0.42$ $\mathrm{kgCO}_{2 \mathrm{e}}$, i.e. $6 \%$ of total emissions), due to more demanding requirements in the online process, necessitating the handling of single pieces. Third, packaging is more important in the online case $\left(0.32 \mathrm{kgCO}_{2 \mathrm{e}}\right.$, i.e. $11 \%$ of total emissions) than in the offline case $\left(0.18 \mathrm{kgCO}_{2}\right.$, i.e. $3 \%$ of total emissions $)$, due to the greater impact of packaging on a small order, which is typical of the e-commerce channel.

\subsection{Sensitivity analysis}

A sensitivity analysis was carried out in order to understand how the results obtained in the base case might vary with changes in the input data. Input data relating to both the consumer profiles (i.e. "fashion addicted", "moderate" and "apathetic") and the retailer features (i.e. size, unsold rate in the store, and store size) were varied. Different scenarios were considered, taking into account all of the possible combinations among the individual alternatives, in order to identify a worst (i.e. with the highest environmental impact) and a best (i.e. with the lowest environmental impact) case scenario, as shown in Table 4. A medium case (i.e. with all of the parameters set to medium values) was also considered.

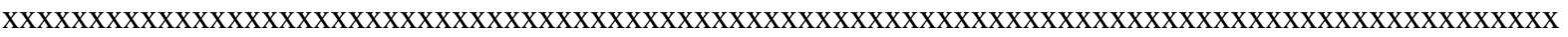

Take in Table 4

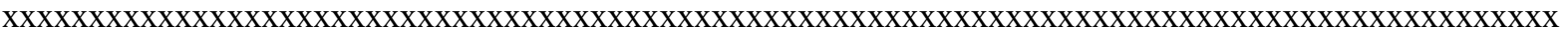


The environmental impact was computed in both the worst and the best case by varying:

- the distance between the consumer house and the store in the offline purchasing process;

- the location of the consumer house, in the online purchasing process.

The results of this sensitivity analysis are shown in Figures 4 and 5.

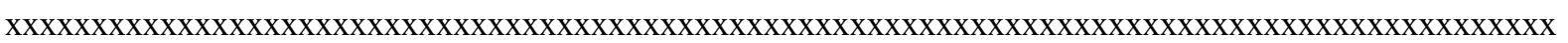

Take in Figure 4

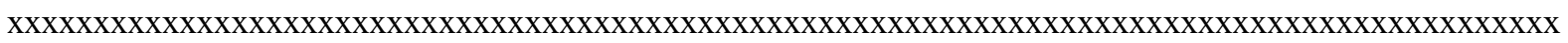

In the online case, the environmental impact can vary between $2.37 \mathrm{kgCO}_{2 \mathrm{e}}$ in the best case, if the consumer house is in the city centre, and $6.48 \mathrm{kgCO}_{2 \mathrm{e}}$ in the worst case and when the consumer house is in an extra-urban area. Firstly, the parameter that affects the environmental impact the most is the location of the consumer house. Ceteris paribus, if the consumer house is located in an extra-urban area then the emissions rise significantly (from 2.37 to $4.27 \mathrm{kgCO}_{2 \mathrm{e}}$ in the best case, from 2.95 to $5.28 \mathrm{kgCO}_{2 \mathrm{e}}$ in the medium case, and from 3.72 to 6.48 $\mathrm{kgCO}_{2 \mathrm{e}}$ in the best case). The main reason is a significant reduction in the delivery density, which means that the express courier can make only 22 drops in four hours in an extra urban area (they can make 40 drops in the city centre), with longer distances to be travelled between two consecutive stops. The last mile delivery is in fact the most important activity in the process from an environmental sustainability perspective, since it could involve between $0.98 \mathrm{kgCO}_{2 \mathrm{e}}$ in the best case and $2.46 \mathrm{kgCO}_{2 \mathrm{e}}$ in the worst case. Secondly, the other parameter that has a large effect on the environmental impact is the profile of the consumer, particularly with respect to the Post-sale activity. Ceteris paribus, if the consumer profile changes from "apathetic" (i.e. with the lowest needs and least number of complexities) to "fashion addicted" (i.e. the most demanding consumer profile), the environmental impact rises from 2.92 to $3.72 \mathrm{kgCO}_{2 \mathrm{e}}$ in the best case, from 2.59 to $3.32 \mathrm{kgCO}_{2 \mathrm{e}}$ in the medium case, and from 2.37 to $3.07 \mathrm{kgCO}_{2 \mathrm{e}}$ in the best case, with an average increase in emissions of $0.74 \mathrm{kgCO}_{2 \mathrm{e}}$.

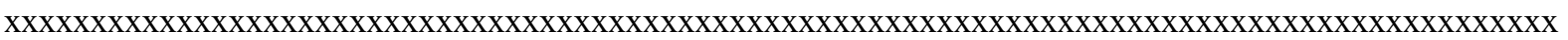
Take in Figure 5

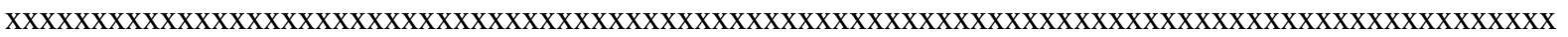


With regard to the offline case, the environmental impact can vary between $2.17 \mathrm{kgCO}_{2}$ in the best case if the consumer house is very close to the store (i.e. $1 \mathrm{~km}$ away), and $12.45 \mathrm{kgCO}_{2 \mathrm{e}}$ in the worst case when the consumer house is $15 \mathrm{~km}$ away from the store $(15 \mathrm{~km}$ is the maximum distance considered, i.e. more than double the average distance). First of all, the input parameter that affects the environmental impact the most is the distance between the consumer house and the store. Ceteris paribus, if this distance increases from 1 to $15 \mathrm{~km}$, emissions increase linearly (as shown in Figure 6) from 6 to $12.45 \mathrm{kgCO}_{2 \mathrm{e}}$ in the worst case, from 3.6 to 10.05 $\mathrm{kgCO}_{2 \mathrm{e}}$ in the medium case, and from 2.17 to $8.62 \mathrm{kgCO}_{2 \mathrm{e}}$ in the best case. This highlights the importance of transport activities in determining the environmental impact: the $\mathrm{CO}_{2 \mathrm{e}}$ emissions generated by the car trip (to get the store and to get back home) as a proportion of the emissions of the whole process varies in the medium case between $10 \%$ (when the distance between the consumer house and the store is $1 \mathrm{~km})$ and $63 \%(15 \mathrm{~km})$.

Secondly, the shift from best to worst case has a large impact on the emissions related to non-logistics activities, which increase from 1.14 to $4.66 \mathrm{kgCO}_{2 e}$, representing $22 \%$ and $52 \%$ of the total impact, respectively. This is due to the fact that store size and consumer features have a significant effect on the environmental impact of all of the in-store activities (e.g. interactions between the consumer and the salesperson, finding and trying on product, etc.). At the same time, the environmental impact of logistics activities increases to a lesser extent, decreasing as a proportion of the total impact while moving from the best to the worst case.

\subsection{Sensitivity analysis: online vs. offline}

The online and the offline processes were compared in order to determine in which cases the environmental emissions of the offline purchasing process are lower than those of the online process.

If the consumer house is in the city centre, the online purchasing process generates lower emissions than those computed for the offline case, no matter what the distance is between the consumer house and the store. If the consumer house is in an extra-urban area, which of the two purchasing processes is more sustainable is highly dependent on the distance between the consumer house and the store, as shown in Figure 6.

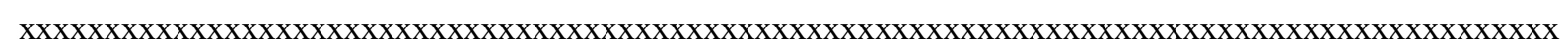

Take in Figure 6

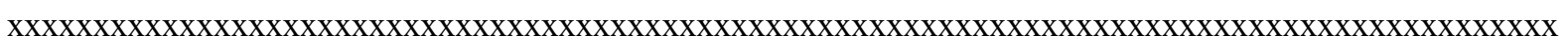

The offline purchasing process, in the worst case, has a lower environmental impact than that observed in the online case only when the consumer house is very close to the store ( $1 \mathrm{~km}$ distant). This is due to the significant 
impact of non-logistics activities on $\mathrm{CO}_{2}$ emissions, which account for a significant proportion of total emissions and are almost equal to the emissions generated by the online purchasing process, no matter what the distance house-store. In the medium and in the best case, the magnitude of the environmental impact related to logistics most of all transport - activities increases, mainly due to a reduction in the emissions created by non-logistics activities $\left(2.5 \mathrm{kgCO}_{2 \mathrm{e}}\right.$ and $1.15 \mathrm{kgCO}_{2 \mathrm{e}}$, respectively). In this context, the overall emissions are greatly impacted by the distance house-store, and the offline purchasing process generates a lower impact than the online process if the distance house-store is less than $4 \mathrm{~km}$ (in the medium case) or $5 \mathrm{~km}$ (in the worst case). However, the online purchasing process is not always more sustainable than the offline process. The comparison between the two is highly sensitive to the location of the consumer house (city centre vs. extra urban area, due to its impact on transport activities in the online case), the distance house-store (due to its influence on transport activities in the offline purchasing process) and the examined (i.e. worst, base, or best) case (mainly due to the impact on the non-logistics activities - i.e. especially those in the store - in the offline purchasing process).

\subsection{Sensitivity analysis: number of items ordered}

Finally, a sensitivity analysis on the number of items ordered by the customer was conducted. Two main assumptions were made: (i) the number of items ranged from 1 to 3 , and (ii) all of the items ordered are available at the warehouse and are delivered in the same parcel to the customer. These assumptions are realistic since: (i) the average number of items ordered online is normally slightly more than 1 , and (ii) as very often happens, only the available items are shown on the website. All of the other conditions remained the same as in the base case (Section. 6.2). The results are shown in Figure 7.

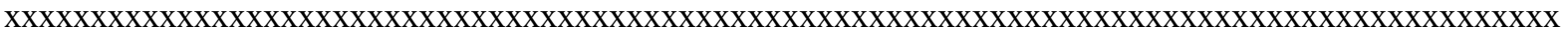

Take in Figure 7

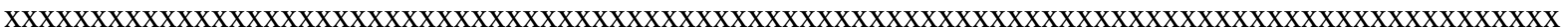

The environmental impact grows less than proportionally with respect to the number of items ordered by customers: $2.95 \mathrm{kgCO}_{2 \mathrm{e}}(1 \mathrm{item}), 4.45 \mathrm{kgCO}_{2 \mathrm{e}}\left(2\right.$ items), and $5.76 \mathrm{kgCO}_{2 \mathrm{e}}(3$ items $)$ in the online case, and 6.62 $\mathrm{kgCO}_{2 \mathrm{e}}\left(1\right.$ item), $9.75 \mathrm{kgCO}_{2 \mathrm{e}}(2$ items $)$, and $12.56 \mathrm{kgCO}_{2 \mathrm{e}}(3$ items $)$ in the offline case. With the exception of warehousing - for which consumption values are divided among the items stored - the environmental impact generated by all of the other activities is less than proportional to the number of items in both the online and offline cases. More specifically, the environmental impact related to packing increases slightly when more items 
are purchased, because it is mainly related to the dimensions of the carton used, which are clearly not proportional to the number of items. Nor does the number of items significantly affect the $\mathrm{CO}_{2 \mathrm{e}}$ emissions from the transport activities, due to the fact that they depend mainly on the distance travelled in both the online and offline cases. The slight increase in the environmental impact of transport activities is related to the increased probability of an item being returned. Handling activities have a greater effect due to the fact that some important activities (e.g. retrieval of the pieces) have an impact that is strictly proportional to the number of items. Finally, the $\mathrm{CO}_{2 e}$ emissions related to non-logistics activities in the offline case increase almost proportionally to the number of items. This is due to the fact that interactions with the salesperson in the shop are directly related to the number of items, while this effect is negligible in the online case.

\section{$7 \quad$ Conclusions}

This paper presents an Activity-Based model that can be used to assess the environmental impact of the purchasing process in the apparel industry, comparing traditional in-store and B2c e-commerce channels with particular attention to logistics activities.

Several significant findings may be highlighted. First, consistently with McKinnon et al. (2012) and Sivaraman et al. (2007), in the base case (i.e. medium sized retailer and store, moderate consumer, and consumer house in the city centre) the online purchasing process has been shown to be more sustainable than the offline process, due to a lower environmental impact in the Pre-sale and sale and the Delivery phases. This is mainly due to (i) computer-based activities - compared to visiting the store - that take place in the Pre-sale phase, (ii) the Sale phase being more sustainable, and (iii) more efficient transport in the last mile delivery. Secondly, the impact of logistics was found to be very high in both types of purchasing processes: $99 \%$ and $62 \%$ of total $\mathrm{CO}_{2 \mathrm{e}}$ emissions are related to logistics activities in the online and offline processes, respectively. Thirdly, those factors that have a significant impact on the $\mathrm{CO}_{2 \mathrm{e}}$ emissions generated by the online and offline purchasing processes were investigated by conducting an in-depth sensitivity analysis. As far as the online case is concerned, the parameter that affects the environmental impact the most is the location of the consumer house, which, due to very different delivery densities in the city centre and in extra-urban areas, strongly affects the last mile delivery (i.e. the most important activity in terms of $\mathrm{CO}_{2 \mathrm{e}}$ emissions in the online purchasing process). Another key factor is the consumer profile, as it can lead to extra activities in the Post-sale phase. As far as the offline case is concerned, the input parameter that affects the environmental impact the most is the distance between the consumer house and the store, due to the impact of the car trip to and from the store. The other parameters (i.e. retailer size, unsold rate in the store, store size and consumer type) mainly influence the environmental impact of 
all the in-store activities (e.g. interactions between consumer and the salesperson, finding and trying on the product, etc.). The online and the offline processes were compared in order to understand when and how the environmental emissions of the offline purchasing process are lower than those of the online process. The results highlighted that if the consumer house is in the city centre, the online purchasing process generates lower emissions compared to those computed for the offline case, no matter what the distance between the consumer house and the store. However, when the consumer house is in an extra-urban area, the online purchasing process is not always more sustainable than the offline process, but, depending on the case considered (i.e. worst, medium, best), the offline case could be more sustainable than the online case if the distance house-store is less than $1 \mathrm{~km}$ (in the worst case), $4 \mathrm{~km}$ (in the medium case) and $5 \mathrm{~km}$ (in the best case). Finally, a further sensitivity analysis was carried out on the number of items ordered by the customer. The results highlighted that all of the activities - with the exception of warehousing - generate an environmental impact that is less than proportional to the number of items in both the online and offline purchasing processes.

The model presented in this paper has both academic and practical implications. From an academic viewpoint, it helps fulfil an identified need to develop comprehensive models to quantify the environmental consequences of e-commerce processes, specifically focusing on the apparel industry. With respect to the extant literature, two main aspects may be highlighted. In terms of the 'sustainability' perspective, the models found in the existing literature on e-commerce are mainly conceptual. Although there are some analytical models, they mainly adopted a 'general' perspective and did not provide any detailed computations of the impact for each activity involved in the purchasing process. In terms of the industry sector investigated, the available models generally focus on sectors that were promising in the past - such as books and DVDs - but have now been overtaken in the current e-commerce scenario, in which other industries - such as apparel, as noted by several sources (e.g. Ha and McGregor, 2013) - have emerged. In addition, because this is a fast-developing area, the results and findings from older studies need to be updated and integrated periodically. This is especially true in light of the fact that the volumes handled through e-retail channels are progressively increasing, and efficiency in terms of process environmental impact (e.g. $\mathrm{CO}_{2}$ e per package) is expected to improve significantly.

From a practical perspective, the model is intended to be a functional and easy-to-use tool for retailers who aim to understand and quantify the environmental consequences of their business. The model can be also useful to practitioners in supporting their internal monitoring procedures. Specifically, it helps clarify how and when the online process is less environmentally sustainable than the offline one, and to identify the actual impact of each activity, with a focus on logistics (i.e. warehousing and transport), which is extremely relevant. 
However, the model has some limitations that should be acknowledged. First, it focuses on a specific industry sector (i.e. apparel), and cannot be applied to other industries. Additionally, a number of assumptions were necessarily made to simplify the calculations (e.g. consumer order includes only one product, folded garment, retailer warehouse used for both the offline and online channels). Second, the purchasing process considered is assumed to be nationally-based, and therefore the impact of international e-commerce was not taken into account. Third, the model only allows a comparison between offline and online channels to be made, and does not take into account multi-channel purchasing.

Based on the aforementioned limitations, the following future developments are suggested: (i) extend the model to include multi-channel purchasing; (ii) build in an international perspective, including e-commerce purchasing from different countries and related complexities; (iii) consider other sectors that show promise for ecommerce in the near future, such as consumer electronics, home furnishing and design, as suggested by Volpe and Spinelli (2012). 


\section{References}

Allen, J. and Browne, M. (2010) Vans and the economy. Project Report. Commission for Integrated Transport. Bruce, G.M. and Daly, L. (2010) 'Innovative process in E-commerce fashion supply chains', Innovative Quick Response Programs in Logistics and Supply Chain Management, pp. 227-241

Brugnoli, G., Mangiaracina, R. and Perego, A. (2009) 'The e-commerce customer journey: a model to assess and compare the user experience of the e-commerce websites', Journal of Internet Banking and Commerce, Vol. 14 No. 3, pp.1-11

Caniato, F., Caridi, M., Crippa, L., and Moretto, A. (2012) 'Environmental sustainability in fashion supply chains: An exploratory case based research', International Journal of Production Economics, Vol. 135 No. 2, pp.659-670

Cardoso, P.R., Costa, H.S. and Novais, L.A. (2010) 'Fashion consumer profiles in the Portuguese market: involvement, innovativeness, self-expression and impulsiveness as segmentation criteria', International Journal of Consumer Studies, Vol. 34 No.6, pp.638-647

Colicchia, C., Marchet, G., Melacini, M. and Perotti, S. (2013) 'Building environmental sustainability: empirical evidence from Logistics Service Providers’, Journal of Cleaner Production, Vol. 59, pp.197-209

DEFRA (2011) 2011 Government GHG Conversion Factors for Company Reporting: Methodology Paper for Emission Factors. https://www.gov.uk/ (Accessed 18 September 2014)

DEFRA (2012) 2012 Government GHG Conversion Factors for Company Reporting: Methodology Paper for Emission Factors. https://www.gov.uk/ (Accessed 18 September 2014)

DEFRA (2013) 2013 Government GHG Conversion Factors for Company Reporting: Methodology Paper for Emission Factors. https://www.gov.uk/ (Accessed 18 September 2014)

eMarketer (2013) Worldwide B2C Ecommerce, 2013 Forecast and Comparative Estimates. http://www.emarketer.com (Accessed 18 September 2014)

ENEA (2010) Indici di benchmark di consumo per tipologie di edificio ad uso commercial grande distribuzione applicabilità di tecnologie innovative nei diversi climi italiani, pp.1-96

De Koster, M.B.M. (2002) The logistics behind the enter click, in Quantitative Approaches to Distribution Logistics and Supply Chain Management, Springer, Berlin.

Edwards, J., McKinnon, A. and Cullinane, S. (2011) 'Comparative carbon auditing of conventional and online retail supply chains: a review of methodological issues', Supply Chain Management: An International Journal, Vol. 16 No.1, pp.57-63

Elkington, J. (1994) 'Towards the sustainable corporation: win-win-win strategies for sustainable development', California Management Review, Vol. 36, pp.90-100

Evans, P.F. and Camus, L. (2010) Western European Online Retail Forecast, 2009 To 2014. [online] Forrester Research. http://www.Forrester.com (Accessed 18 September 2014)

García-Arca and Prado-Prado (2010) 'Is the concept of agility extendable to all fashion companies?', International Journal of Logistics Systems and Management, Vol. 7 No. 3, pp. 302-323

Ghezzi, A., Mangiaracina, R. and Perego, A. (2012) 'Shaping the e-Commerce logistics strategy: a decision framework’, International Journal of Engineering Business Management, Vol. 4 No. 13, pp.1-13

Ha, H. and McGregor, S.L.T. (2013) 'Role of Consumer Associations in the Governance of E-commerce Consumer Protection', Journal of Internet Commerce, Vol. 12 No. 1, pp.1-25

Hart, S.L. and Milstein, M.B. (2003) 'Creating sustainable value', Academy of Management Perspectives, Vol. 17 No. 2, pp.56-67

Hjort, K., Lantz, B., Ericsson, D. and Gattorna, J. (2013) 'Customer segmentation based on buying and returning behavior’, International Journal of Physical Distribution \& Logistics Management, Vol. 43 No. 10, pp.852-865

Mangiaracina, R. and Perego, A. (2009) 'Payment systems in the B2c e-commerce: are they a barrier for the online customer?', Journal of Internet Banking and Commerce, Vol. 14 No. 3, pp.1-16

Mangiaracina, R., Perego, A. and Campari, F (2012) 'Factors influencing B2c e-commerce diffusion', World Academy of Science, Engineering and Technology, Vol. 65, pp.311-319 
Mangla, S., Madaan, J., Sarma, P.R.S., and Gupta, M.P. (2014) 'Multi-objective decision modelling using interpretive structural modelling for green supply chains', International Journal of Logistics Systems and Management, Vol. 17 No. 2, pp.125-142.

Matthews, H.S., Hendrickson, C.T. and Soh, D.L. (2001) 'Environmental and economic effects of e-Commerce: a case study of book publishing and retail logistics', Transportation Research Record: Journal of the Transportation Research Board, Vol. 1763 No. 1, pp.6-12

McLeod, F., Cherret, T. and Song, L. (2006) 'Transport impacts of local collection/delivery points', International Journal of Logistics Research and Applications: A Leading Journal of Supply Chain Management, Vol. 9 No. 3, pp.307-317

McKinnon, A., Browne, M. and Whiteing, A. (2012) Green logistics: Improving the Environmental Sustainability of Logistics, Kogan Page.

Mouratidis, H. and Cofta, P. (2010) 'Practitioner's challenges in designing trust into online systems', Journal of Theoretical and Applied Electronic Commerce Research, Vol. 5 No. 3, pp.65-77

Mudgal,R.K., Shankar, R., Talib, P., and Raj, T. (2010) 'Modelling the barriers of green supply chain practices: an Indian perspective', International Journal of Logistics Systems and Management, Vol. 7 No. 1, pp.81-107.

Mulpuru, S. (2013) The state of retailing online 2013: key metrics and initiatives, Forrester Research.

Park, M. and Regan, A. (2004) Issues in home delivery operations, University of California, Transportation Center, Los Angeles.

Park, E.J., Kim, E.Y., Funches, V.M. and Foxx, W. (2012) 'Apparel product attributes, web browsing, and eimpulse buying on shopping websites', Journal of Business Research, Vol. 65 No. 11, pp.1583-1589

Perotti, S., Zorzini, M., Cagno, E. and Micheli, G.J. (2012) 'Green supply chain practices and company performance: the case of 3PLs in Italy', International Journal of Physical Distribution \& Logistics Management, Vol. 42 No. 7, pp.640 - 672

Porter, M.E. and Kramer, M.R. (2006) 'Strategy and society: the link between competitive advantage and corporate social responsibility', Harvard Business Review, Vol. 84, pp.78-92

Primerano, F., Taylor, M.A.P., Pitaksringkarn, L. and Tisato, P. (2008) 'Defining and understanding trip chaining behaviour', Transportation, Vol. 35 No. 1, pp.55-72

Qudrat-Ullah, H. (2013) 'Exploring the locus of profitable outsourcing: the case of US apparel industry', International Journal of Logistics Systems and Management, Vol. 15 No. 4, pp.321-337.

Rodiguez-Ardura, I., Meseguer-Artola, A. and Vilaseca-Requena, J. (2008) 'Factors influencing the evolution of electronic commerce: an empirical analysis in a developed market economy', Journal of Theoretical and Applied Electronic Commerce Research, Vol. 3 No. 2, pp.18-29

Samarrokhi, A., Jenab, K., Arumugam, V.C., and Weinsier, P.D. (2014) 'A new model for achieving sustainable competitive advantage through operations strategies in manufacturing companies', International Journal of Logistics Systems and Management, Vol. 19 No. 1, pp.115-130.

Shao, T. and Liu, Z. (2012) 'How to maintain the sustainability of an e-commerce firm? From the perspective of social network', International Journal of Networking and Virtual Organizations, Vol. 11 No. 3, pp.212-224

Sivaraman, D., Pacca, S., Mueller, K. and Lin, J. (2007) 'Comparative energy, environmental, and economic analysis of traditional and e-commerce DVD rental networks', Journal of Industrial Ecology, Vol. 11 No. 3 , pp.77-91

Smith, A.D. (2012) 'Green manufacturing in the packaging and materials industry: case study of small-tomedium sized corporate eco-friendly initiatives', International Journal of Logistics Systems and Management, Vol. 11 No. 4, pp.429-449.

Smithers, R. (2007) Supermarket home delivery service promotes its green credentials. The Guardian. http://www.theguardian.com/environment/2007/sep/12/plasticbags.supermarkets (Accessed $18^{\text {th }}$ February 2014)

Taniguchi, E. and Kakimoto, Y. (2003) 'Effects of e-commerce on urban distribution and the environment', Journal of the Eastern Asia Society for Transportation Studies, Vol. 5, pp.2355-2366

Williams, E. and Tagami, T. (2003) 'Energy use in sales and distribution via e-commerce and conventional retail: a case study of the Japanese book sector', Journal of Industrial Ecology, Vol. 6 No. 2, pp. 99-114

Volpe, A. and Spinelli, M. (2012) E-Commerce for the furniture industry, Centre for Industrial Studies (CSIL). 
Wei, Z. and Zhou, L. (2011) 'Case Study of Online Retailing Fast Fashion Industry', International Journal of eEducation, e-Business, e-Management and e-Learning, Vol. 1 No. 3, pp.195-200

Zeng, C. and Xu, D. (2010) 'Views on the Development of E-Commerce of Chinese Clothing Industry', International Journal of Business and Management, Vol. 5 No. 8, pp.215-218 


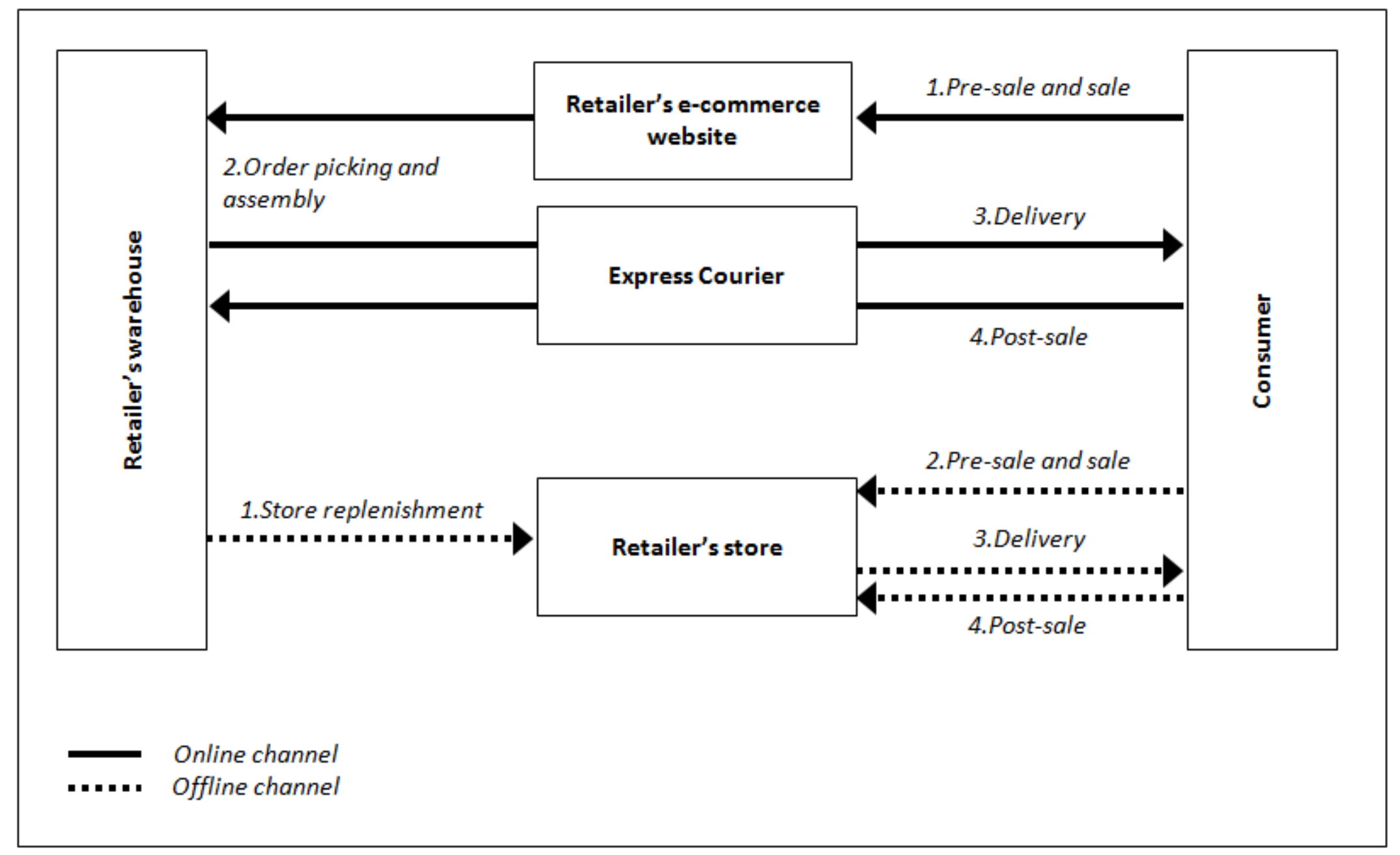

Figure 1 - The purchasing process in the online and offline channels 


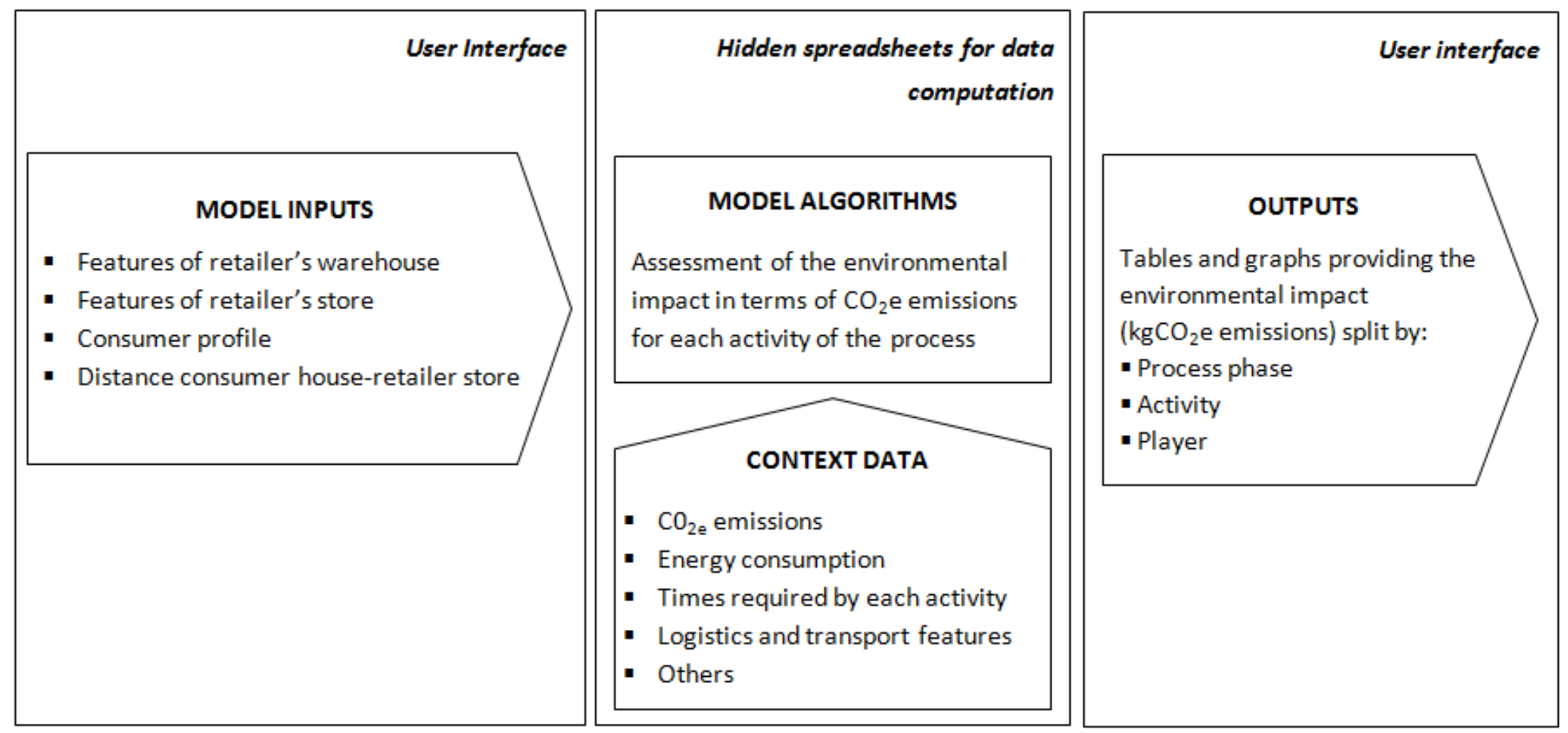

Figure 2-Model architecture 


\begin{tabular}{|c|c|c|c|}
\hline Activity & Activity type & Player & Formula \\
\hline Product pick up & Transport & $\begin{array}{l}\text { Express } \\
\text { courier }\end{array}$ & impact $\left[\frac{\mathrm{kgCO}_{2} \mathrm{e}}{\mathrm{km}}\right] \times$ average distance per parcel pick up route $[\mathrm{km}]$ \\
\hline Info request & Communication & Consumer & impact $\left[\frac{\mathrm{kgCO}_{2} \mathrm{e}}{\mathrm{kWh}}\right] \times$ activity time $[\mathrm{h}] \times$ avg pc power supply $[\mathrm{kW}]$ \\
\hline $\begin{array}{l}\text { Interaction with } \\
\text { consumer }\end{array}$ & Communication & Retailer & impact $\left[\frac{\mathrm{kgCO}_{2} \mathrm{e}}{\mathrm{kWh}}\right] \times$ activity time $[\mathrm{h}] \times$ avg pc power supply $[\mathrm{kW}]$ \\
\hline Tracking & Communication & $\begin{array}{l}\text { Express } \\
\text { courier }\end{array}$ & impact $\left[\frac{\mathrm{kgCO}_{2} \mathrm{e}}{\mathrm{kWh}}\right] \times$ activity time $[\mathrm{h}] \times$ avg pc power supply $[\mathrm{kW}]$ \\
\hline Consolidation & $\begin{array}{l}\text { Warehousing } \\
\text { /handling }\end{array}$ & Retailer & impact $\left[\frac{\mathrm{kgCO}_{2} \mathrm{e}}{\mathrm{kWh}}\right] \times$ total energy consumption per item in the hub $\left[\frac{\mathrm{kWh}}{\mathrm{item}}\right]$ \\
\hline Line haul & Transport & Retailer & impact $\left[\frac{\mathrm{kgCO}_{2} \mathrm{e}}{\mathrm{km}}\right] \times$ average distance per parcel line haul $[\mathrm{km}]$ \\
\hline Sorting & $\begin{array}{l}\text { Warehousing/ } \\
\text { handling }\end{array}$ & Retailer & impact $\left[\frac{\mathrm{kgCO}_{2} \mathrm{e}}{\mathrm{kWh}}\right] \times$ total energy consumption per item in sorting hub $\left[\frac{\mathrm{kWh}}{\mathrm{i} \text { tem }}\right]$ \\
\hline $\begin{array}{l}\text { Customer } \\
\text { delivery }\end{array}$ & Transport & $\begin{array}{l}\text { Express } \\
\text { courier }\end{array}$ & impact $\left[\frac{\mathrm{kgCO}_{2} \mathrm{e}}{\mathrm{km}}\right] \times$ average distance per parcel $[\mathrm{km}]$ \\
\hline
\end{tabular}

Table 1 -Example of the spreadsheet structure for the computation of the 'Delivery' phase in the online purchasing process 


\begin{tabular}{|c|c|c|}
\hline Context data & Description & Figures \\
\hline \multirow{6}{*}{$\begin{array}{l}\text { Energy } \\
\text { consumption }\end{array}$} & Average PC power supply $[\mathrm{kW}]$ & 0.1 \\
\hline & Warehouse energy consumption $\left[\mathrm{kWh} /\left(\mathrm{m}^{3}\right.\right.$ year $\left.)\right]$ & 48.5 \\
\hline & Annual energy consumption pro-capite [kWh/year $]$ & 1,186 \\
\hline & Annual energy consumption in store $\left[\mathrm{kWh} /\left(\mathrm{m}^{3}\right.\right.$ year $\left.)\right]$ & 48.5 \\
\hline & Hub energy consumption $\left[\mathrm{kWh} /\left(\mathrm{m}^{3}\right.\right.$ year $\left.)\right]$ & 48.5 \\
\hline & Table of environmental certification $\left[\mathrm{kWh} /\left(\mathrm{m}^{3}\right.\right.$ year $\left.)\right]$ & I \\
\hline \multirow{5}{*}{$\mathrm{CO}_{2 \mathrm{e}}$ emissions } & Van (diesel-class II: $1,3-3,5 \mathrm{t})\left[\mathrm{kgCO}_{2 \mathrm{e}} / \mathrm{km}\right]$ & \multirow{5}{*}{$\begin{array}{l}\text { Defra } \\
\text { Reports }\end{array}$} \\
\hline & Rigid truck (diesel, $>17 \mathrm{t}$ ) $\left[\mathrm{kgCO}_{2} / \mathrm{km}\right]$ & \\
\hline & Articulated truck (diesel, $3,5-33 \mathrm{t})\left[\mathrm{kgCO}_{2 \mathrm{e}} / \mathrm{km}\right]$ & \\
\hline & Car (diesel, medium size) $\left[\mathrm{kgCO}_{2 \mathrm{e}} / \mathrm{km}\right]$ & \\
\hline & Grid Rolling Average $\left(\left[\mathrm{kgCO}_{2 \mathrm{e}} / \mathrm{kWh}\right]\right.$ & \\
\hline \multirow{20}{*}{ Times } & Search of the product online $[\mathrm{s}]$ & 300 \\
\hline & Check of product availability, size, and color [s] & 120 \\
\hline & Information request to the merchant (mail) [s] & 180 \\
\hline & Reply to customer email [s] & 300 \\
\hline & Selection of the product (into cart) [s] & 30 \\
\hline & Input of information in the cart $[\mathrm{s}]$ & 120 \\
\hline & Input of the information for returns [s] & 120 \\
\hline & Input of the payment information $[\mathrm{s}]$ & 120 \\
\hline & Emission of a replenishment order by the POS [s] & 900 \\
\hline & Management of the replenishment in the POS [s] & 300 \\
\hline & POS order fulfilment $[\mathrm{s}]$ & 600 \\
\hline & Emission of the picking list (for POS orders) [s] & 600 \\
\hline & Request of information about the delivery by POS [s] & 60 \\
\hline & Reception/management of product/return [s] & 30 \\
\hline & Consumer order fulfilment $[\mathrm{s}]$ & 120 \\
\hline & Emission of the picking list (for consumer order) [s] & 60 \\
\hline & Request of information about the delivery by consumer [s] & 60 \\
\hline & Interaction merchant- consumer [s] & 60 \\
\hline & Manual packaging of returns $[\mathrm{s}]$ & 180 \\
\hline & Verification of product noncompliance $[\mathrm{s}]$ & 180 \\
\hline \multirow{9}{*}{$\begin{array}{l}\text { Logistics and } \\
\text { transport } \\
\text { features }\end{array}$} & Hub size $\left[\mathrm{m}^{2}\right]$ & 10,000 \\
\hline & Fulfilled orders per day [orders/day] & 1,000 \\
\hline & Average no. of cartons in the line haul [cartons /trip] & 2,640 \\
\hline & Average no. of cartons per delivery route [cartons /route] & 22 \\
\hline & Average no. of cartons per pick-up route [cartons/route] & 252 \\
\hline & Average distance of the delivery trip $[\mathrm{km}]$ & 150 \\
\hline & Average distance of the pick-up trip [km] & 50 \\
\hline & Average distance per carton in delivery trip $[\mathrm{km} /$ carton] & 6.8 \\
\hline & Average distance per carton in pick-up trip [km/carton] & 0.198 \\
\hline \multirow{9}{*}{ Others } & Number of search engines/comparison websites visited by consumer & \\
\hline & Average time at home in a day [hr/day] & 11 \\
\hline & Store annual opening days & 300 \\
\hline & Warehouse/branch annual working days & 250 \\
\hline & Distance store-outlet $[\mathrm{km}]$ & 80 \\
\hline & Store height $[\mathrm{m}]$ & 5 \\
\hline & Warehouse/branch height $[\mathrm{m}]$ & 9 \\
\hline & Shipping area online height $[\mathrm{m}]$ & 4 \\
\hline & Average store return rate $[\%]$ & 1 \\
\hline
\end{tabular}

Table 2- Main contextual datarelated to the base case 


\begin{tabular}{|c|c|c|c|}
\hline Retailer features & High & Medium & Low \\
\hline Warehouse size $\left[\mathrm{m}^{2}\right]$ & 32,000 & 20,000 & 13,000 \\
\hline Fulfilled orders per day (in the warehouse) & 2,000 & 1,000 & 500 \\
\hline Store size $\left[\mathrm{m}^{2}\right]$ & 500 & 350 & 125 \\
\hline Flow of people in the store per day & 400 & 280 & 100 \\
\hline Unsold rate in the store [\%] & $30 \%$ & $20 \%$ & $10 \%$ \\
\hline Warehouse energy rating & $\mathrm{E}$ & $\mathrm{E}$ & $\mathrm{E}$ \\
\hline Store energy rating & $\mathrm{E}$ & $\mathrm{E}$ & $\mathrm{E}$ \\
\hline Type of consumer & $\begin{array}{c}\text { Fashion } \\
\text { addicted }\end{array}$ & Moderate & Apathetic \\
\hline Number of websites visited before buying & 5 & 3 & 2 \\
\hline Number of stores visited before buying & 5 & 3 & 2 \\
\hline Number of garments tried on & 10 & 5 & 2 \\
\hline Number of interactions with the online retailer & 5 & 2 & 0 \\
\hline $\begin{array}{l}\text { Number of interactions with the salesperson in the } \\
\text { store }\end{array}$ & 2 & 1 & 0 \\
\hline Returns [\%] & $30 \%$ & $20 \%$ & $10 \%$ \\
\hline Location of consumer house & City & & Extra urban area \\
\hline Distance consumer house - store & \multicolumn{3}{|c|}{ From $1 \mathrm{~km}$ to $15 \mathrm{~km}$} \\
\hline
\end{tabular}

Table 3 - Input data related to the scenarios examined 

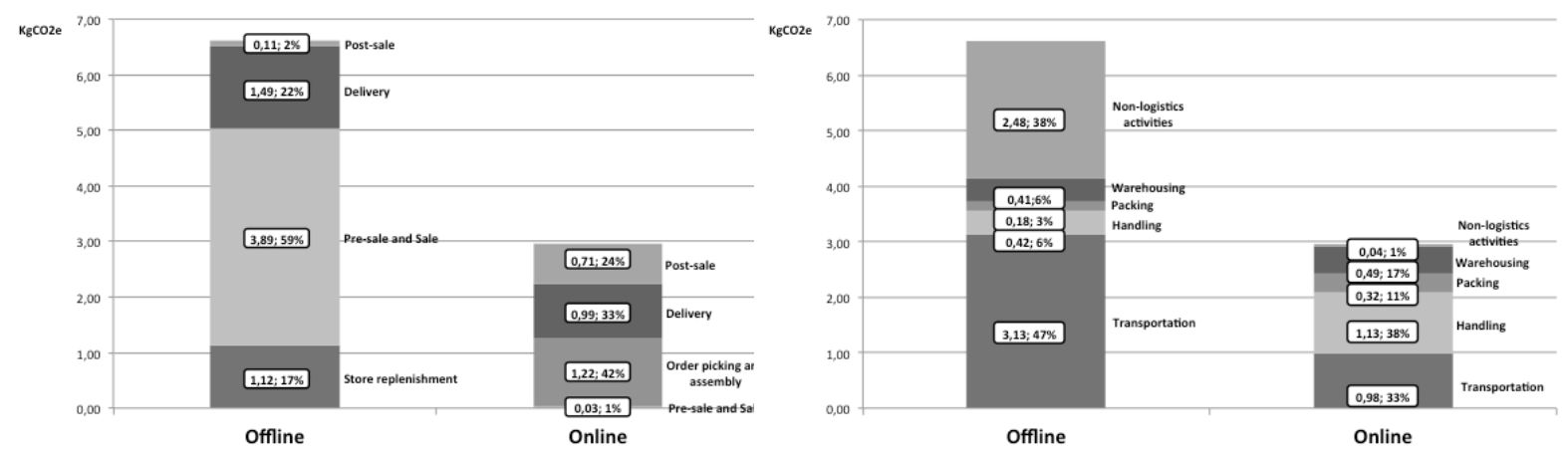

Figure 3 -Environmental impact $\left(\mathrm{kgCO}_{2 \mathrm{e}}\right)$ of the online and offline purchasing processes: base case 


\begin{tabular}{lccc}
\hline & Worst case & Medium case & Best case \\
Type of retailer & & & \\
\hline Size of the retailer & Small & Medium & Large \\
Unsold rate in the store & High & Medium & Low \\
Store size & Small & Medium & Large \\
\hline Type of consumer & Fashion addicted & Moderate & Apathetic \\
\hline
\end{tabular}

Table 4- Sensitivity analysis: cases examined 
Extra-urban Area

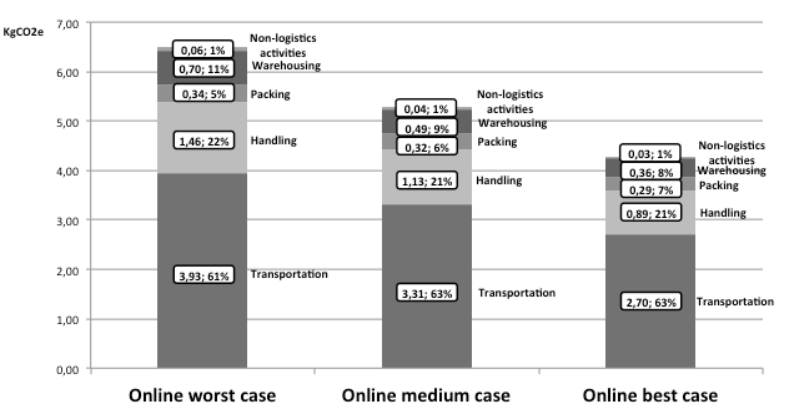

City Centre

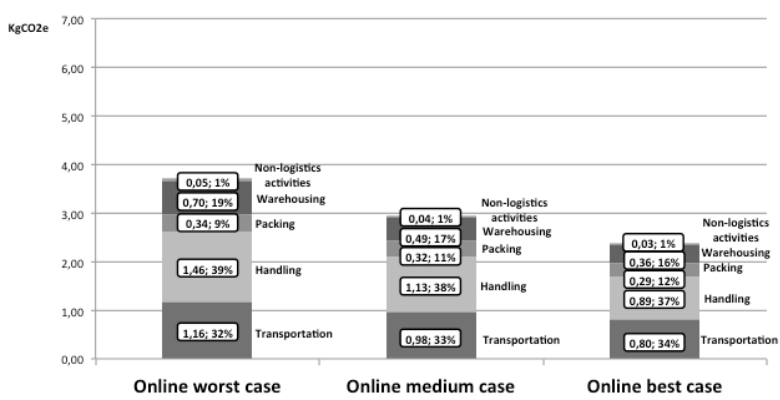

Figure 4- Sensitivity analysis results for the online purchasing process 

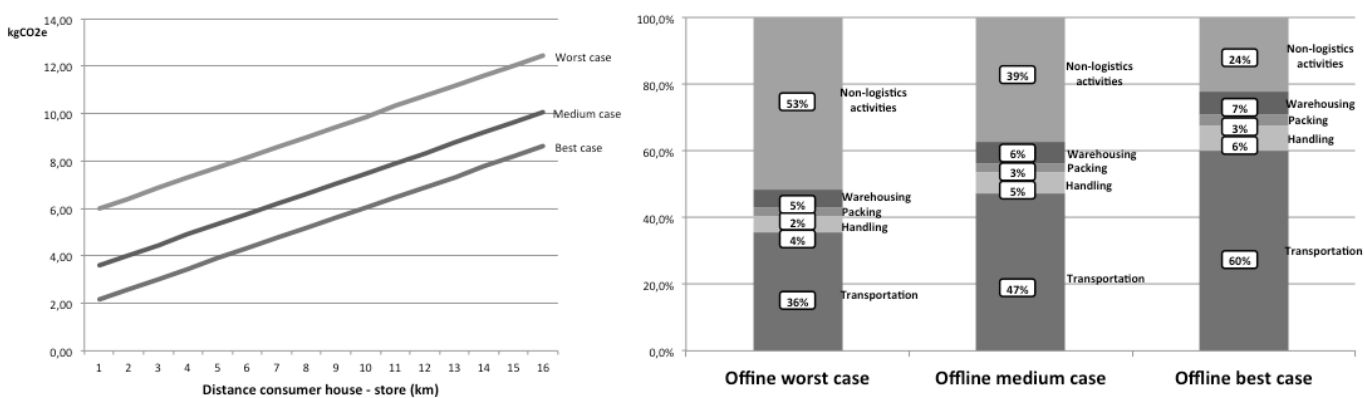

Figure 5 - Sensitivity analysis results for the offline purchasing process 
Worst case

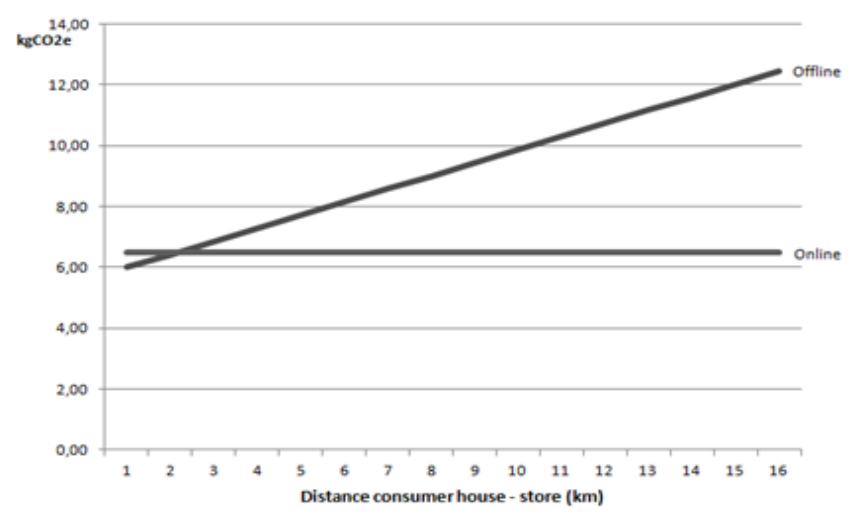

Medium case

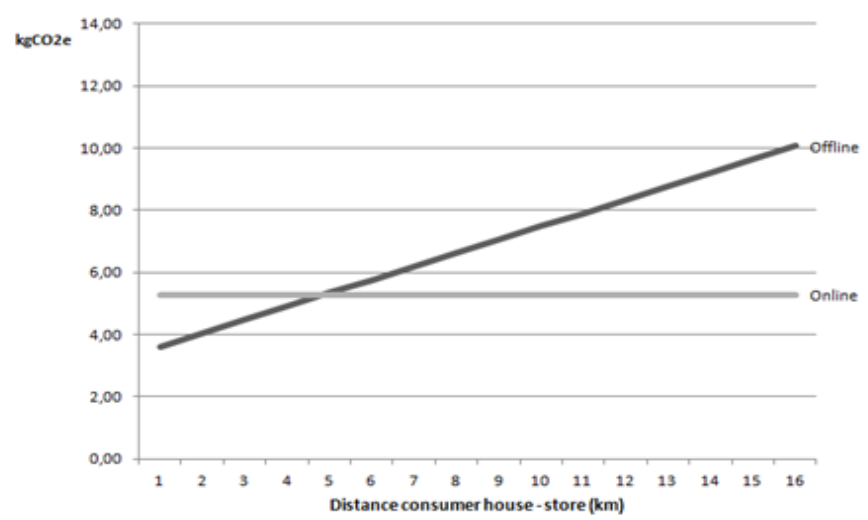

Best case

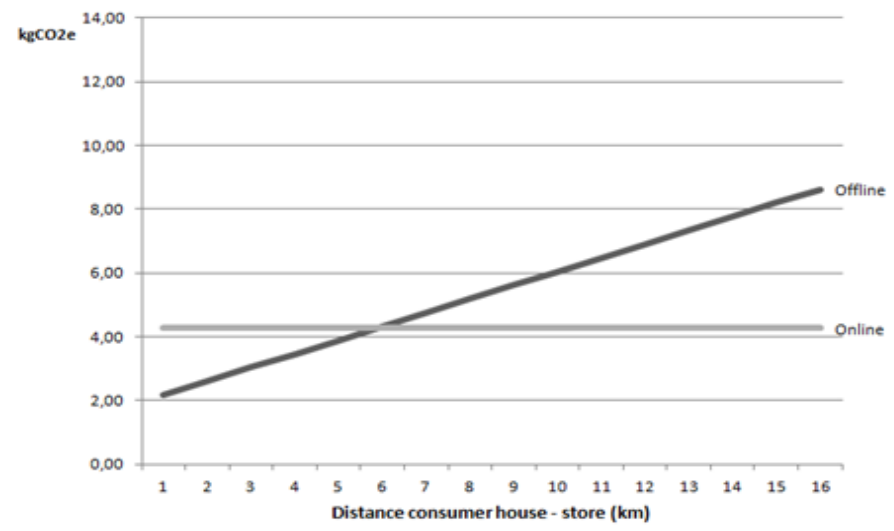

Figure 6 - Offline vs. online cases when consumer house is in an extra-urban area: comparison of the environmental impact for different scenarios 


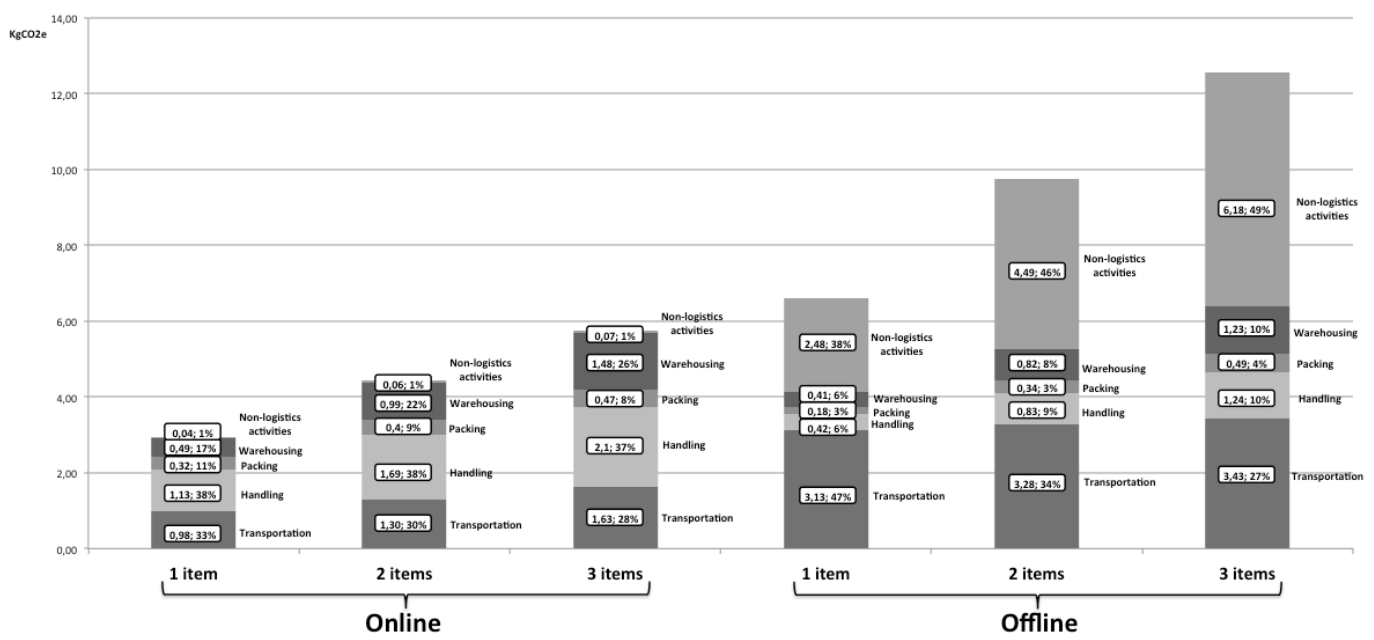

Figure 7 - Results of the sensitivity analysis on number of items ordered by the customer 